\title{
Predictors of Family Function in DMD and SMA Family
}

\author{
Jih Y. Chen ${ }^{1 *}$, Ming H. Yen², Ying H. Lin ${ }^{3}$, Meng C. Liu ${ }^{3}$, Hong S. Chen ${ }^{4}$, Shu H. Hu ${ }^{5,6}$, Yea Y. Liu ${ }^{1}$ \\ ${ }^{1}$ School of Nursing, Kaohsiung Medical University, Taiwan \\ ${ }^{2}$ School of Dentist and Graduate Institute for Oral Health Science, Kaohsiung Medical University; Pediatric Dentist, Kaohsiung Medical University Hospital, Taiwan \\ ${ }^{3}$ Department of Nursing, Kaohsiung Medical University \& Chung-Ho Memory Hospital, Taiwan \\ ${ }^{4}$ Department of Oral Hygiene, School of Dentist and Graduate Institute for Oral Health Science, Kaohsiung Medical University, Taiwan \\ ${ }^{5}$ Department of Medical Laboratory Science and Biotechnology, Kaohsiung Medical University, Taiwan \\ ${ }^{6}$ Nutrient, Kaohsiung Medical University Hospital, Taiwan ROC
}

Received: September 21, 2015; Accepted: December 21, 2015; Published: December 30, 2015

*Corresponding author: Jih-Yuan Chen, College of Nursing, Kaohsiung Medical University100, Shih-Chuan 1st Rd. Kaohsiung, Taiwan, ROC 80761, Tel: +011-886-7-3121101-2610; Fax: +011-886-7-3218364; E-mail: jiyuch@kmu.edu.tw

\begin{abstract}
Introduction: The progressive disability creates a low quality of life for families of children with muscular dystrophy. The families experience family overload, resulting in the alienation of family members and the common occurrence of caregiver burden, and resulting economic burden.
\end{abstract}

Purpose: The purposes of the study were to identify the differences in family characteristics, health needs, lifestyle, and overall family health status between cohorts of families with a child from either Duchenne muscular dystrophy (DMD) or spinal muscular dystrophy (SMA). And analyzed the predictive factors influence the major health-associated variables.

Methods: Analyzes were conducted on data derived from 86 of families with DMD or SMA. Participants (113, mean age: 42.68 years) included the patient's parents, siblings, and other caregivers of children with DMD and SMA. The data were obtained using selfreported questionnaires.

Results: The results show that family support, family hardiness, the power to propose an idea/plan, and family incomes are predictors for family functioning. Gender, education, income, time spent watching TV, and the power to propose an idea or plan constituted important characteristics influencing this model of family health and family function.

Conclusion: The results of this knowledge are important for development of professional strategies and treatment plans.

Keywords: Family Health Promotion Pattern; Family Health; Family Hardiness; Family Support; DMD; SMA

\section{Introduction}

Duchenne Muscular Dystrophy (DMD) is an inherited recessive X-linked disorder from a mutation or deficiency in Xp21-dystrophin. The resulting deficiency causes muscle degeneration and eventual death in patients with DMD [1]. It is estimated that one in every 3,600 boys is at risk for developing DMD [2]. Symptoms of DMD include muscle and joint contracture and deformity, as well as loss of muscle mass and physical strength that is a frequent cause of respiratory infections. The resulting decline in muscle mass may affect school achievement, social relationship and activities, or cause anxiety or depression in affected children. The associated physical and social components of the disease often case language difficulties or intellectual disability [2] DMD patients. The progressive disability creates a low quality of life for both the children and their families and become increasingly dependent on caregivers for assistance with normal daily tasks. Commonly, families with a child who has DMD experience Family overload, resulting in the alienation of family members and the common occurrence of caregiver burden. Moreover, the continuous stress of caring for a child with DMD can lead to parental self-esteem and body image issues, negatively affecting the parent's ability to maintain normal social relationships. Furthermore, the physical stress of caring for DMD children can negatively impact a parent's work performance, decrease his or her sex drive, and result in a loss of self-discipline [3]. Therefore, the resulting conflict within the Families of patients with DMD can significantly affect the quality of life for the individual, as well as his or her family members $[3,4]$.

Spinal Muscular Atrophy (SMA) is loss of function of motor neurons in the anterior horn of human spinal cord. SMA is an autosomal recessive disorder resulting from the inheritance of a genetic defect in the SMN1 gene and it is estimated to affect approximately one in every 6000 people [5]. There are four identified forms of SMA which differ with respect to the age of onset and the symptom severity. Symptoms of SMA include weakness of the extremities and body trunk resulting in a loss of neck control, difficulty swallowing, a loss of the deep tendon reflex, and an inability to sit or stand. Often, SMA is linked to neurological symptoms, muscle weakness, and impaired lung Function [6], which makes daily activities more difficult for families with a child that has SMA. Additionally, SMA patients can have significant respiratory difficulties resulting from the weakness of the respiratory muscles. Moreover, the respiratory weakness limits the ability of SMA patients to clear nasopharyngeal secretions that is a frequent cause of respiratory infections and pneumonia [5,7-9]. SMA Type II in this study is associated with a more severe disability, leading to enhanced care needs. The thoughts and actions of a physically challenged 
child or adolescent are highly influenced by the behavior of his or her parents, thereby impacting his or her attitude towards the illness.

Typically, families with a child who has SMA experience difficulty maintaining a healthy family dynamic. This can result in destructive behavior and increased overall stress within the family. The overall feelings (negative or positive) of the family unit can significantly impact the quality of life for both the child and his or her family. These feelings can negatively impact the actions of Family Health Promotion (FHP). FHP focuses on increasing afflicted families awareness of the importance of overall family health and provides specific information concerning the rehabilitation and medical-care needs related to their child's disability, as well as promotes the importance of both emotional and physical interfamily support. If the parents maintain a positive outlook, the child maintains a sense of security which promotes behaviors of self-efficacy that can significantly influence his or her interpersonal relationships with family, peers, and health care providers.

The FHP reinforces the need for both mental and social support within the family unit. When dealing with a family that has a child with DMD or SMA, FHP should become a major focus [10]. Specifically, an FHP system must assess the specific health risks, nutrition needs, family hardiness, family support, and overall lifestyle of the gamily in question, which derived family health capacity, family health status, health needs, and family health lifestyle pattern variables via assessing family stress, resources, and adaptation [4] . Typically, the family assessment device and the duke health evaluation presnt family health status that have been used to elucidate the features associated with the FHP model [3,4,10-12]. Family hardiness and family support present family health capacity present family resources that have been also used with the FHP model [4].

Family hardiness is a resilience capacity that relates to the ability of a family to face adversity, and is subjected to continuous adjustment and adaptation $[13,14]$. Family support is considered to be the care and support of family members that live together. Family support in the context of caring for family members is evaluated based on how well the members perceive that their needs are being met [13]. The purpose of this study is 1) to identify the differences in health status and FHP system variables, members of families with a child who has DMD to those who have a child with SMA; 2) to explore the predictive Factors inFluence Family general Function.

\section{Methods}

\section{Sample}

In this study, we included only the families who had a child with DMD or SMA (the diagnosis was confirmed by muscle biopsy and DNA genetic screen), and all members of the family (parents, patients, siblings, or major primary caregivers) who agreed to participate could communicate in mandarin or Taiwanese. A family was excluded if any other member had a serious medical condition, or if any individuals under the age of 20 years refused to participate in the study. In total, 42 families of children with
DMD ( $n=55)$ and 44 families of children with SMA $(n=58)$ were included in the study. The distribution of participants was similar in both studies, and surveys were collected From 83 parents, four siblings, and five caregivers, as well as 21 patients suffering from either DMD or SMA.

\section{Design}

Participants completed a questionnaire that measured:

1) The demographics

2) Self-reported health status (Duke Health Profile-17 items) [15] and family general function (Family Assessment DeviceGeneral Function, FAD-GF) which included the 12 items from the Family Assessment Device (FAD) [16]

3) Family health needs, including the personal health risk factors of body structure, Body Mass Index (BMI), and lumbar/ waist ratio; and a nutrition assessment that included: BMI condition, health risk problem, body weight assessment, nutrition condition, and health risk;

4) Family structure analysis consisting of family types, family development stages, family power structure, location, employment, and education;

5) Family health capacities, including family hardiness, were measured by the Family Hardiness Index of 20 items $[17,18]$. In addition, family support was measured by the family APGAR by five items $[19,20]$.

6) Family health behaviors were measured by a health promoting lifestyle pattern consisting of 40 items [21].

\section{Measures}

Family Health Needs Assessment (FHNS): To assess FHNS, body structure (height/wrist ratio: small-male: $>10.4 \mathrm{~cm}$; small Female: > $11 \mathrm{~cm}$; medium male: $9.6-10.4 \mathrm{~cm}$; medium Female: 10.1-11 cm; large male: $<9.6 \mathrm{~cm}$; and large Female $<10.1 \mathrm{~cm}$ ), Body Mass Index (BMI), and lumbar/waist ratio were measured. A nutritional assessment was also performed, which included: BMI condition (starvation: < 18.5; malnutrition: < 19; healthy body weight: $=19-25$; overweight: $=26-27$; health risk crisis increased: = 28 - 30; and illness/obesity: > 30), health risk level (increase: waist circumference: $>=35$ inch for Females and $>$ $=40$ inch for males; or decreased: < 35 inch for females and < 40 inch For males), body weight assessment (compare to ideal body weight: obesity: > 20\%; overweight: > 10-20\%; normal: $<$ or $>10 \%$; underweight: $<10-20 \%$; and emaciated: < 20\%), nutrition condition (body weight/ideal body weight ratio: severe malnutrition: $<70 \%$; moderate malnutrition: $=70-79 \%$; mild malnutrition: $=80-89 \%$; normal: $=90-109 \%$; overweight: $=110-$ $120 \%$; and obese: $>120 \%$ ), health risk (lumbar/waist ratio: high health risk: males > .95 and Females > .85; moderate health risk: males $=.90-.95$ and Female $=.80-.85$; and low health risk: males $<.90$, Females $<.80$.

Family Structure Analysis: Family types included nuclear, expended, single, reorganized, cohabitating, and living with others. Family developmental stages included families of children 
in preschool, school-aged, adolescent, adult, or retired. Family power structure included the power to propose an idea or plan with direct, indirect, silence, or direct and indirect responses. Residence location included rural, suburban/town, and urban residences. Employment included professional, government/ administrator, or technique/labor/none. Monthly income included less than NT\$30,000, NT\$30,000- NT\$50,000 and greater than NT\$50,000. Education included less than or equal to nine years or over 12 years. Amount of time spent watching TV included zero hours, one to three hours, or over three hours. Family power structure included 1) decision-making by parents or others; 2) problem solving by parents or others; and 3) the power to propose an idea or plan by direct, indirect, silent, or both direct and indirect methods.

Health Promotion Lifestyle Pattern (HPLP): To measure Family health behaviors used by HPLP, 40 items on a five-point Likert scale were ranked from one (not at all) to five (always) [21]. In all six subscales (nutrition, exercise, health responsibility, stress management, social support, and life appreciation), higher scores indicate a better lifestyle, with a score ranging between 40 and 200 [22]. The internal consistency reliabilities of the HPLP scale and its subscales in this study ranged from .75 to .95 , and their item total correlations ranged from .35 to .69 .

Family Hardiness Index (FHI) and Family APGAR (FAPGAR): we observed: 1) the 20 items from the FHI, which contained three subscales to survey commitment, challenge, and control using self-report. This report involved a four-point Likert scale with values of zero (False), one (most False), two (most true) and three (true), with a higher score indicating a greater degree of family hardiness $[17,18]$. The internal consistency reliabilities of the FHI scale were adequate (alpha $=.82$ ) with its subscales ranging from .50 to .79 . With a score ranging of $0-60$, their construct validity ranged from .70 to .86, and their item total correlation ranged From .69 to .80 ; and 2) the five items from the FAPGAR were used to measure adaptation, partnership, growth, affective, and overall resolve using a threepoint scale, including zero (hardly ever), one (some of the time), and two (almost always), higher scores were indicative of a greater overall satisfaction with perceived level of family support $[19,20]$. The internal consistency reliabilities of the FAPGAR scale were adequate (alpha $=.90$ ), with a score ranging from 0 to 10 . The construct validity and the AVE of the scale were .90 and .65 , respectively.

Family Assessment Device - general Function (FAD-GF) and Duke Health Profile (DHP): To measure the functional status of each family, the 12 items of the FAD-GF were graded using a four-point Likert scale that ranged from one (strongly agree) to four (strongly disagree). A lower score indicated a healthy family [16]. The internal consistency reliability of the FAD-GF scale was adequate (alpha $=.89$ ). The construct validity and AVE of the scale were .99 and .92, respectively.

In addition, the 17 items of the DHP were evaluated using a Likert scale (ranging from 0 to 2), consisting of positive functional health (physical, social, mental, perceived health, and self-esteem) and negative functional health (anxiety, depression, combined anxiety-depression, pain, and disability) [15]. Participants chose from one of three options that indicated the extent to which a specific statement described them, for example $0=$ "no = does not describe me at all," 1 = "describes me somewhat," and $2=$ "describes me exactly." Others were rated for the extent of the difficulty experienced in an area, in which " 2 = none, 1 = some, and $0=$ a lot", or rated in terms of frequency during a one week period, in which " $0=$ none, $1=$ sometimes, $2=$ a lot, and $0=5$ to 7 days, $1=1$ to 4 days, and $2=$ none" [23]. The internal consistency reliabilities of the DHF scale was adequate (alpha $=.77$ ) and its subscales ranged from .41 to .66 , with a score ranging from 0 to 100 (all item scores were transformed to a raw score from 0,1 , and 2 into 0,50 , and 100, respectively). The construct validity of the scale was acceptable (.83).

\section{Procedure}

The procedures performed and informed consent sheets in this study were approved by the Kaohsiung medical university hospital institute review board (KMUH-IRB-20110397). Participants were recruited by the clinical staffs who obtained the initial consent for the participation using a telephone call to the patient's family. Interested families were screened to determine whether every family member over 20 years was willing to participate. After they had agreed to be inducting in the study, a data package was mailed to each family. The package contained general study information, informed consent sheets to be signed and returned, questionnaires, and pre-stamped return envelopes for the completed surveys. Members were contacted if a completed package was not returned within two weeks. Researchers continued to communicate with the patient's family until the package was returned.

\section{Statistical analysis}

Data were analyzed using IBM SPSS Version 21. The total sample size consisted of 113 individuals, including 55 in the DMD group and 58 in the SMA group. In addition, 29 participants were fathers, 54 were mothers, 21 were the patients themselves, and nine were siblings (or other caregivers of the patient). The baseline characteristics of the two groups were compared using an independent sample t-test for continuous data, a Pearson chi-square for categorical variables with a moderate effect size $(\mathrm{d}=.53)$, and an F-test for variables with a large effect size $(\mathrm{d}=$ .40). In addition, a two-tailed significance test with a power of .8 and a level of .05 was also performed [24,25]. Variables were used to identify potential correlates of the family functionality on the basis of bivariate analyses. Model assumptions and levels of goodness-of-fit were assessed via a graphical check.

\section{Results}

Table 1 presents the characteristics of the participants and their respective families. Participants were primarily parents of an affected child (74\%), Taiwanese (83\%), nuclear family $(65 \%)$, female (58\%), in the adolescent family development stage (54\%), and had direct power to propose an idea or plan (71\%). Approximately three-quarters had completed over 12 years 
Table 1: Demographic data of the participants and their family $(n=113)$.

\begin{tabular}{|c|c|c|c|c|c|c|c|}
\hline Variables & Classification & \multicolumn{2}{|c|}{ DMD (n = 55) } & \multicolumn{2}{|c|}{ SMA $(n=58)$} & T test $\mathbf{p}$ & $X^{2}(p)$ \\
\hline \multicolumn{2}{|l|}{ Parent age $($ mean $=45.89, \mathrm{SD}=7.27)$} & \multicolumn{2}{|c|}{$44.87(7.23)$} & \multicolumn{2}{|c|}{$47.11(7.22)$} & 1.41 .16 & \\
\hline \multicolumn{2}{|l|}{ Case age $($ mean $=32, S D=9.70)$} & \multicolumn{2}{|c|}{$26.75(2.36)$} & \multicolumn{2}{|c|}{$33.24(10.40)$} & 1.21 .24 & \\
\hline \multicolumn{2}{|l|}{ Sibling age $($ mean $=23, \mathrm{SD}=3.56)$} & \multicolumn{2}{|c|}{$21.50(2.12)$} & \multicolumn{2}{|c|}{$24.50(4.95)$} & .79 .51 & \\
\hline \multicolumn{2}{|l|}{ Caregiver age $($ mean $=50, S D=4.43)$} & \multicolumn{2}{|c|}{$53.50(7.0)$} & \multicolumn{2}{|c|}{$36(\mathrm{~N} / \mathrm{A})$} & & \\
\hline \multicolumn{2}{|l|}{ Female $(n=65)$} & \multicolumn{2}{|c|}{$31(56.4 \%)$} & \multicolumn{2}{|c|}{$38(58.6 \%)$} & & .59 .81 \\
\hline \multirow[t]{5}{*}{ Participation } & Father & 17 & 30.9 & 12 & 20.7 & & 10.71 .03 \\
\hline & Mother & 28 & 50.9 & 26 & 44.8 & & \\
\hline & Patient & 4 & 7.3 & 17 & 29.3 & & \\
\hline & Sibling & 2 & 3.6 & 2 & 3.4 & & \\
\hline & Caregiver & 4 & 7.3 & 1 & 1.7 & & \\
\hline \multirow[t]{3}{*}{ Geography } & North & 24 & 43.6 & 12 & 20.7 & & 6.95 .03 \\
\hline & Middle & 9 & 16.4 & 15 & 25.9 & & \\
\hline & South & 22 & 40.0 & 31 & 53.4 & & \\
\hline Ethnicity & Taiwanese & 37 & 67.3 & 57 & 98.3 & & 19.86 .00 \\
\hline & Haika & 5 & 9.1 & 1 & 1.7 & & \\
\hline & Chinese & 12 & 5.8 & & & & \\
\hline & Foreigner & 1 & 1.8 & & & & \\
\hline Marital status & Married & 41 & 76.4 & 36 & 62.1 & & 3.62 .31 \\
\hline & Separated & 1 & 1.8 & 1 & 1.7 & & \\
\hline & Divorce & 4 & 7.3 & 4 & 6.9 & & \\
\hline & Single & 17 & 14.5 & 17 & 29.3 & & \\
\hline Education & $<=9$ years & 18 & 32.7 & 13 & 22.4 & & $3.70 \quad 30$ \\
\hline & 12 years & 20 & 36.4 & 18 & 31.0 & & \\
\hline & 14 years & 9 & 16.4 & 11 & 19.0 & & \\
\hline & >=16years & 8 & 14.5 & 16 & 27.6 & & \\
\hline Occupation & Professional & 3 & 5.5 & 2 & 3.4 & & $5.03 \quad 28$ \\
\hline & Government & 7 & 12.7 & 10 & 17.2 & & \\
\hline & Administrator & 7 & 12.7 & 10 & 17.2 & & \\
\hline & Technique & 8 & 14.5 & 2 & 3.4 & & \\
\hline & Labor, none & 30 & 54.5 & 34 & 58.6 & & \\
\hline Monthly income & $<30,000$ & 17 & 30.9 & 22 & 37.9 & & $6.04 \quad .42$ \\
\hline & $30,000-40,000$ & 14 & 25.5 & 10 & 17.2 & & \\
\hline & $40,000-50,000$ & 7 & 12.7 & 2 & 3.4 & & \\
\hline & $50,000-60,000$ & 7 & 12.7 & 7 & 12.1 & & \\
\hline & $60,000-70,000$ & 4 & 7.3 & 8 & 13.8 & & \\
\hline & $70,000-80,000$ & 1 & 1.8 & 1 & 1.7 & & \\
\hline & $>80,000$ & 5 & 9.1 & 8 & 13.8 & & \\
\hline Time spent watching TV & 0 hour & 7 & 12.7 & 3 & 5.2 & & $2.72 \quad .44$ \\
\hline & 1-3 hour & 36 & 65.5 & 45 & 77.6 & & \\
\hline & 4-7 hour & 11 & 20.0 & 9 & 15.5 & & \\
\hline & $>8$ hour & 1 & & 1 & 1.7 & & \\
\hline Residence location & Rural & 12 & 21.8 & 22 & 37.9 & & 3.64 .30 \\
\hline & Suburban & 5 & 9.1 & 5 & 8.6 & & \\
\hline & Town & 7 & 12.7 & 5 & 8.6 & & \\
\hline & Urban & 31 & 56.4 & 26 & 44.8 & & \\
\hline Family structure & Nuclear & 28 & 50.9 & 45 & 77.8 & & 10.71 .06 \\
\hline & Expended & 21 & 38.2 & 8 & 13.8 & & \\
\hline & Single & 3 & 5.5 & 3 & 5.2 & & \\
\hline & Reorganization & 1 & 1.8 & 1 & 1.7 & & \\
\hline & Cohabitation & 1 & 1.8 & 1 & 1.7 & & \\
\hline & Living with others & 1 & 1.8 & 0 & 0.0 & & \\
\hline Family development & Preschool & 4 & 7.3 & 2 & 3.4 & & 14.48 .01 \\
\hline
\end{tabular}




\begin{tabular}{|c|c|c|c|c|c|c|}
\hline & School & 11 & 20.0 & 7 & 12.1 & \\
\hline & Adolescent & 35 & 63.6 & 26 & 44.8 & \\
\hline & Adult & 4 & 7.3 & 20 & 34.5 & \\
\hline & Retired & 1 & 1.8 & 3 & 5.2 & \\
\hline \multirow[t]{7}{*}{ Decision maker } & Father & 17 & 30.9 & 21 & 36.2 & 7.39 .29 \\
\hline & Mother & 15 & 27.3 & 14 & 24.1 & \\
\hline & Grandfather & 1 & 1.8 & 1 & 1.7 & \\
\hline & Grandmother & 3 & 5.5 & 0 & 0.0 & \\
\hline & Others & 6 & 10.9 & 13 & 22.4 & \\
\hline & Mother \& father & 12 & 21.8 & 9 & 15.5 & \\
\hline & $\begin{array}{l}\text { Father \& } \\
\text { grandmother }\end{array}$ & 1 & 1.8 & 0 & 0.0 & \\
\hline \multirow[t]{7}{*}{ Problem solving } & Father & 17 & 30.9 & 16 & 27.6 & 15.02 .02 \\
\hline & Mother & 11 & 20.0 & 17 & 29.3 & \\
\hline & Grandmother & 4 & 7.3 & 0 & 0.0 & \\
\hline & Mother \& grandfather & 5 & 9.1 & 0 & 0.0 & \\
\hline & Mother \& father & 10 & 18.2 & 7 & 12.1 & \\
\hline & Others & 8 & 14.5 & 17 & 29.3 & \\
\hline & $\begin{array}{l}\text { Father \& } \\
\text { grandmother }\end{array}$ & 0 & 0.0 & 1 & 1.7 & \\
\hline \multirow[t]{4}{*}{ Propose idea or plan } & Direct & 44 & 80.0 & 36 & 62.1 & 5.89 .12 \\
\hline & Indirect & 9 & 16.4 & 16 & 27.6 & \\
\hline & Silence & 2 & 3.6 & 3 & 5.2 & \\
\hline & Direct \& indirect & 0 & 0.0 & 3 & 5.2 & \\
\hline \multicolumn{7}{|c|}{$\begin{array}{l}\text { Chi-square tests were used to compare categorical variables, } p=\text { values may be unstable when cells sizes are below } 5 \text {. } \\
\text { Values are presented as (n\%) / (pearson- } \mathrm{x}^{2} \mathrm{p} \text {-values) }\end{array}$} \\
\hline
\end{tabular}

of education and had a monthly income exceeding NT\$30,000. There were no significant differences in the variables associated with gender, parental age, patient age, sibling age, marital status, education level, employment status, family income; time spent watching TV, residence location, family structure, decisionmaking, problem-solving, or the power to propose idea or plan between DMD and SMA groups (Table 1). Primarily parents, females, Taiwanese, nuclear families, and in an adolescent development stage were variables directly related to the power to propose an idea/plan. Young and unmarried women constituted an important part of the labor pool in the study. Family monthly income provides a substantial indication of family economics, in which the majority of women in the study returned home and many elected to remain in the labor Force.

In addition, there are no significant differences in the family nutritional assessment of both groups, including BMI condition $\left(x^{2}=4.57, p=.33\right)$, health risks (e.g., body Fat) $\left(x^{2}=.52, p=.47\right)$, body weight assessment $\left(x^{2}=.80, p=.67\right)$, other potential health risks (lumbar/waist ratio) $\left(x^{2}=5.16, p=.08\right)$, and body structure $\left(x^{2}=.38, p=.14\right)$. Similarly, there were no differences observed for the height/wrist ratio $(t=.64, p=.34)$, BMI $(t=-.89, p=.40)$, or the bodyweight minus ideal body weight between two groups ( $t=-.83, p=.41$ ), with the exception of the lumbar/waist ratio $(t=2.25, p=.03)$. The sample did not exhibit any significant differences in the family health promotion assessment, FHPL $(t=$ $.25, p=.08)$, DHP ( $t=1.31, p=.19)$, FHI $(t=1.12, p=.26)$, FAPGAR $(t=-.43, p=.67)$, or FAD- GF $(t=-.46, p=.65)$ Five scales scores, including their subscales ( $t$-test $=-.43 \sim 1.37$ and $p=.17 \sim .75)$ between the DMD and SMA groups.

Similar comparisons were performed using the means obtained for the five-point scales, including their subscales with means for participant's classification (fathers, mothers, patients, siblings, and caregivers) between the DMD and SMA groups. Again, there were no significant differences found between the mean scores, and the p-values of F-value test ranged from .17 0.8 (Figure 1-3). According to the above findings, no significant differences were found between the two groups of diseases for all variables. Therefore, the authors combined the data from both groups to predict the related factors for the promotion of healthy lifestyles in families of children with muscular dystrophy.

Table 2 shows correlations between all variables among demographics, FHPL, Duke Health profile, FHI, FAPGAR, and FADGF. Results show that social-demographic characteristics have an association with level of FAPGAR in relation to geography in Taiwan, as well as between gender, and the power to propose a plan or idea. The level of the Duke Health profile was correlated with monthly family income $(r=.22, p<.05)$, education $(r=.23, p<$ $.05)$, and time spent watching TV $(r=.34, p<.01)$. The score of the FAD-GF indicated a positive relationship between monthly family income $(r=-.20, p<.05)$ and the power to propose an idea or plan $(r=-.46, p<.01)$. The HPLP score revealed a positive relationship between monthly family income $(r=.20, p<.05)$, education $(r=$ $.26, p<.01)$, and the power to propose an idea or plan $(r=.26, p$ $<.01)$. Any inconsistencies in the results were related to the level of FHI accepted by the family structure $(r=.19, p<.05)$. The focus 

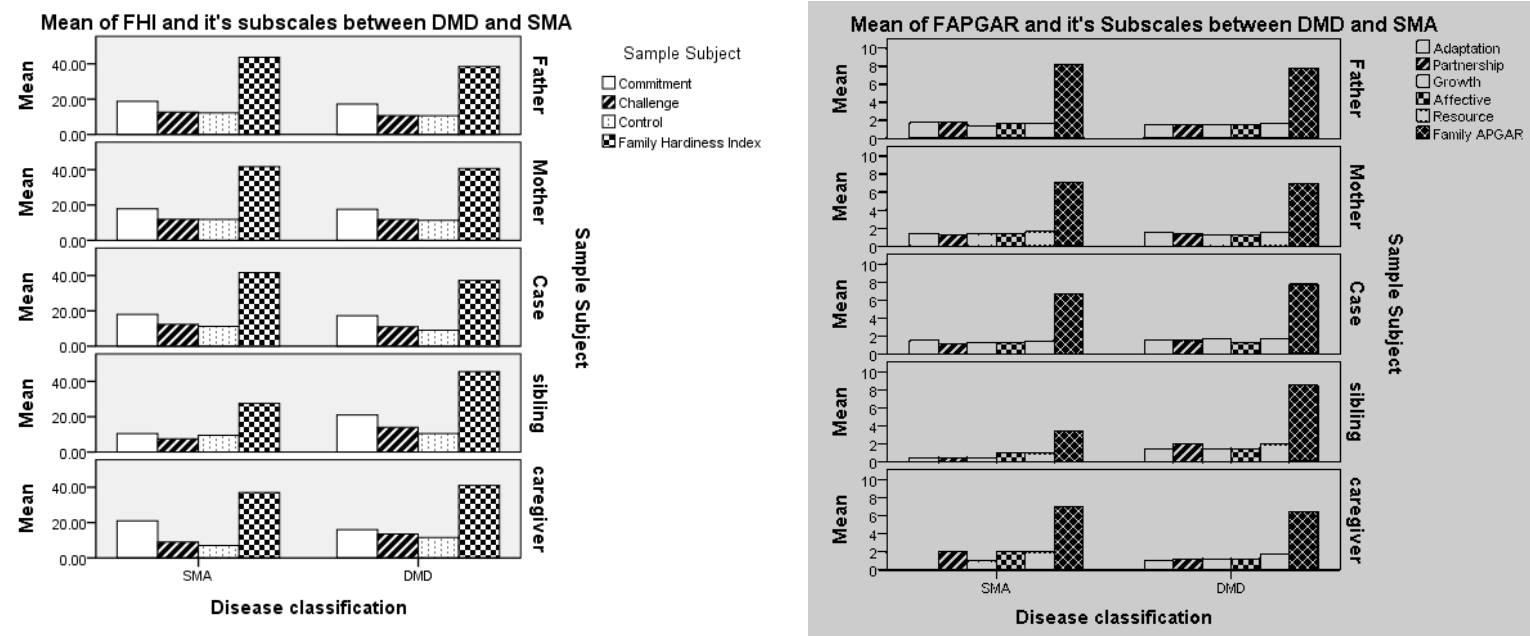

Figure 1: Scale means by group in FHI and FAPGAR. There were no significant differences between DMD and SMA subject classifications.

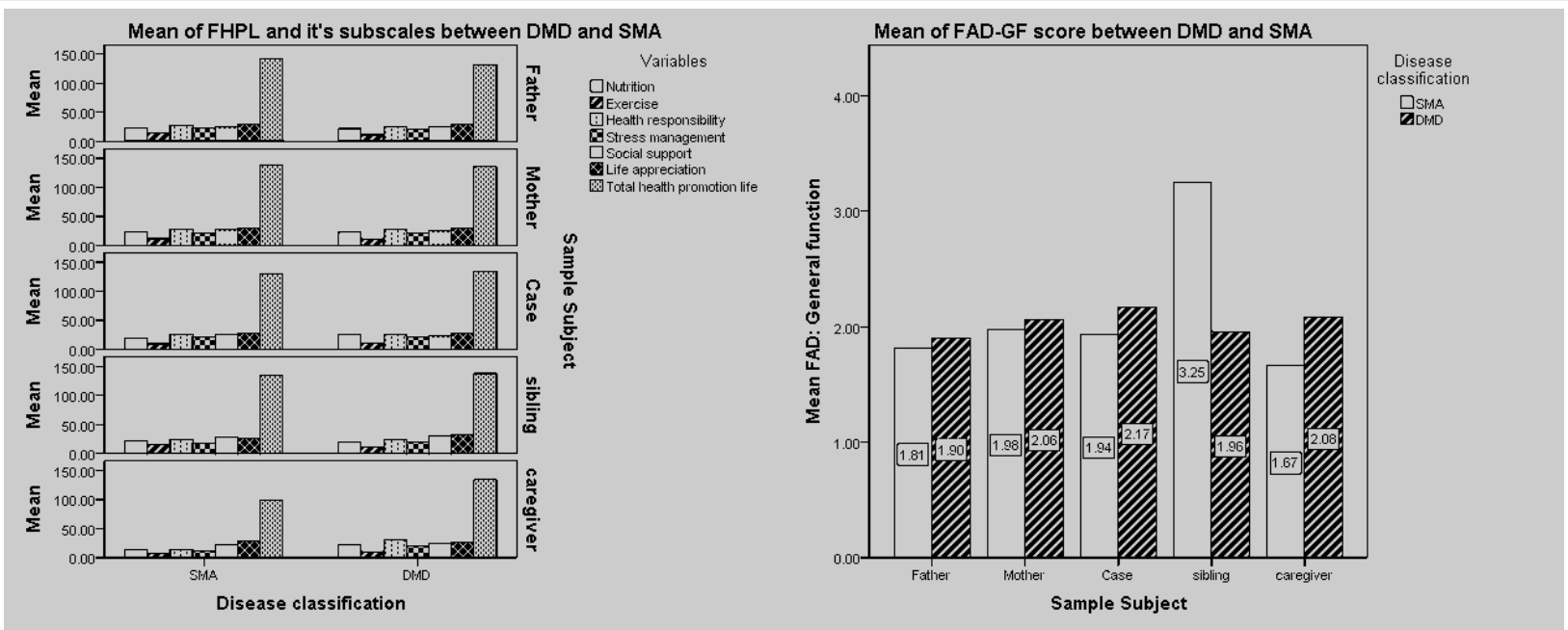

Figure 2: Scale means by group in FHPL and FAD-GF. There were no significant differences between DMD and SMA subject classifications.

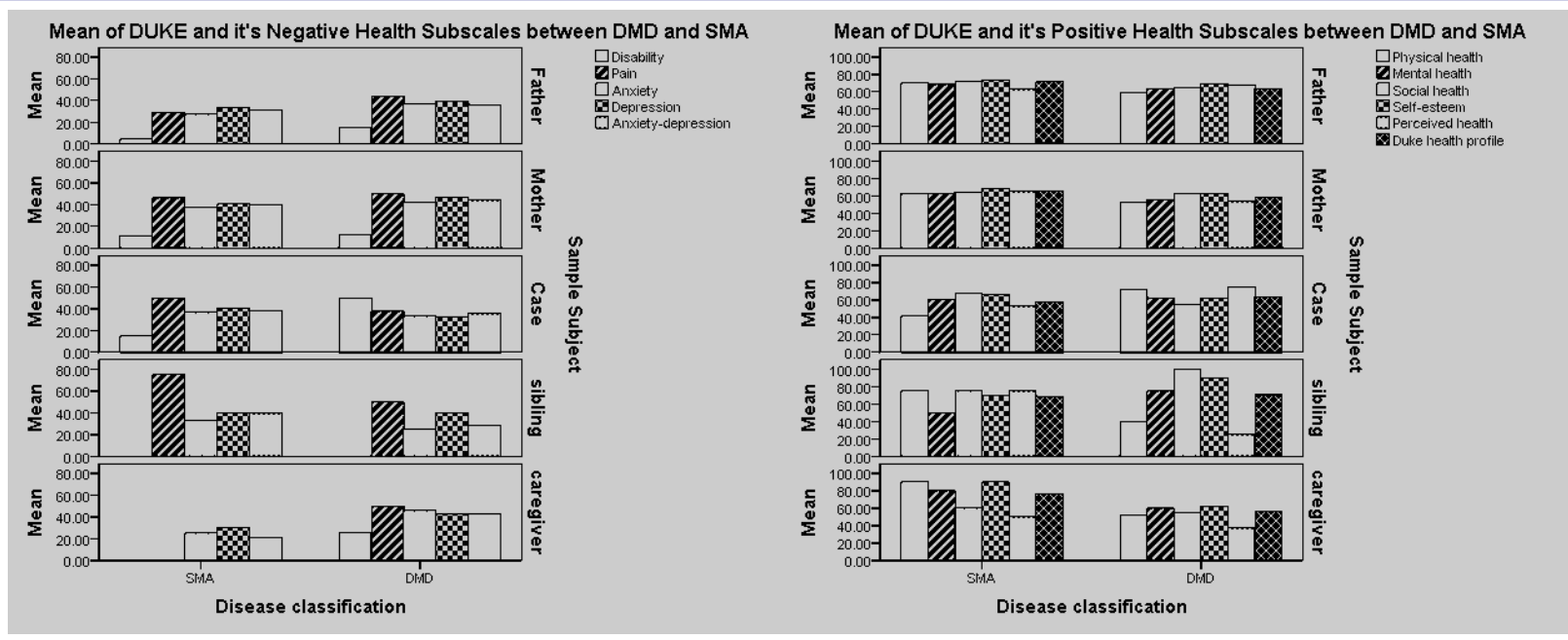

Figure 3: Scale means by group in DUKE. There were no significant differences between DMD and SMA subject classifications. 


\begin{tabular}{|c|c|c|c|c|c|c|c|c|c|c|c|c|c|}
\hline & Geography & Gender & $\begin{array}{l}\text { Monthly } \\
\text { income }\end{array}$ & Education & $\begin{array}{l}\text { Watching } \\
\text { TV-time }\end{array}$ & Location & $\begin{array}{c}\text { Family } \\
\text { structure }\end{array}$ & \begin{tabular}{|c|} 
Power \\
to \\
propose
\end{tabular} & $\begin{array}{c}\text { Health } \\
\text { promotion } \\
\text { life }\end{array}$ & \begin{tabular}{l|} 
Family \\
APGAR
\end{tabular} & \begin{tabular}{|c|} 
Duke \\
health \\
profile
\end{tabular} & \begin{tabular}{|c|} 
Family \\
Hardiness \\
Index
\end{tabular} & $\begin{array}{c}\text { FAD: } \\
\text { General } \\
\text { function }\end{array}$ \\
\hline Geography & 1 & & & & & & & & & & & & \\
\hline Gender & .077 & 1 & & & & & & & & & & & \\
\hline $\begin{array}{l}\text { Monthly } \\
\text { income }\end{array}$ & .069 & .152 & 1 & & & & & & & & & & \\
\hline Education & -.019 & .173 & $.412^{* *}$ & 1 & & & & & & & & & \\
\hline TV time & -.062 & .038 & .065 & .101 & 1 & & & & & & & & \\
\hline Location & -.076 & .028 & $.215^{*}$ & .008 & -.177 & 1 & & & & & & & \\
\hline \begin{tabular}{|l} 
Family \\
structure
\end{tabular} & .106 & .000 & $.192^{*}$ & .025 & .027 & .020 & 1 & & & & & & \\
\hline $\begin{array}{l}\text { Power to } \\
\text { propose }\end{array}$ & -.030 & -.017 & -.074 & .056 & .101 & .076 & .015 & 1 & & & & & \\
\hline $\begin{array}{l}\text { Health } \\
\text { promotion } \\
\text { life }\end{array}$ & .092 & -.065 & $.197^{*}$ & $.258^{* *}$ & .121 & .036 & .049 & $.256^{* *}$ & 1 & & & & \\
\hline $\begin{array}{l}\text { Family } \\
\text { APGAR }\end{array}$ & $.212^{*}$ & $.210^{*}$ & .049 & .067 & -.004 & .039 & .115 & $.466^{* *}$ & $.445^{* *}$ & 1 & & & \\
\hline $\begin{array}{l}\text { Duke } \\
\text { health } \\
\text { profile }\end{array}$ & .080 & .154 & $.216^{*}$ & $.228^{*}$ & $.344^{* *}$ & -.122 & .038 & $.204^{*}$ & $.511^{* *}$ & $.510^{* *}$ & 1 & & \\
\hline $\begin{array}{l}\text { Family } \\
\text { Hardiness } \\
\text { Index } \\
\end{array}$ & .052 & -.057 & .151 & .149 & .126 & -.056 & $.187^{*}$ & $.210^{*}$ & $.565^{* *}$ & $.444^{* *}$ & $.413^{* *}$ & 1 & \\
\hline $\begin{array}{l}\text { FAD: } \\
\text { General } \\
\text { function }^{\#}\end{array}$ & .017 & -.109 & $-.195^{*}$ & -.135 & -.079 & -.079 & -.135 & $-.456^{* *}$ & $-.528^{* *}$ & $-.640^{* *}$ & $-.498^{* *}$ & $-.737^{* *}$ & 1 \\
\hline
\end{tabular}

for family power structures was to directly provide an idea or suggestion (i.e., the power to propose an idea or plan) associated with five scales (Table 2). In addition, the participants' nutritional assessments (e.g., the assessment of the family health needs), including body structure (height/ wrist ratio), BMI, and body weight judgment (actual bodyweight minus ideal bodyweight), and no association with the levels found via the five scales ( $r=$ $.001 \sim 1.68$ and $p=.17 \sim .99$ ), with the exception of health risks (lumbar/waist ratio, $r=-.24$ and $p=.02$ ) which correlated with the scores for health promotion life pattern.

Table 3 shows the hierarchical linear regression was used to determine the relative contribution of family general Function:

1) In step one, 10 independent variables of participant characteristics were added.

2) In step two, family hardiness and family support were added to step one.

3) In step 3, Duke Health was added.

4) Finally, family health behavior was added to step 3. The final regression statistic for the full model were significant predictors of the power to propose an idea or plan (beta $=.16$, $\mathrm{t}=2.80, \mathrm{p}=.01$ ), monthly income (beta $=-.11, \mathrm{t}=-2.06, \mathrm{p}=$ .04 ), family hardiness (beta $=-.55, \mathrm{t}=-9.12, \mathrm{p}=.00$ ), and family support (beta $=-.33, \mathrm{t}=-5.12, \mathrm{p}=.00$ ) on family general function
$(\mathrm{F}=62.42, \mathrm{p}=.00$, and $\mathrm{R}=.84)$. Above four variables together accounted for $69.72 \%$ of variance in family general function.

\section{Discussion}

In the study, the scale ratings between the two muscular dystrophy groups and five different clusters of family members were analyzed by a t-test or ANOVA. Internal consistency reliabilities and construct validity of these measures were also determined to be acceptable. The total item correlations were found to be adequate. These scales were moderately correlated with one another ( $r=.4$ to .7).

Family members differ in their opinions regarding health and illness related to family health behaviors, support, hardiness, general functionality, and overall health. The findings suggest that there are no significant differences in the five-scale scores of family health promotion assessment including the subscales between DMD and SMA families. Similar results were achieved for the five-scale scores, including their subscales among participant classification of fathers, mothers, cases, siblings, and caregivers. All of the 113 participants' eligible family demographic information was analyzed together. However, the statistical data of the study did not present any significant differences in individual characteristics, family characteristics, or family nutrition assessment variables, with the exception of health risks (lumbar/waist ratio) between DMD and SMA groups. 
Table 3: Hierarchical regression to determine contributors of family general function by family characteristics, family support, family hardiness, general health, and family promotion of healthy lifestyles.

\begin{tabular}{|c|c|c|c|c|c|c|c|c|}
\hline & & B & SE & Beta & t-value & $\mathbf{P}$ & R-value & ANOVA F (P) \\
\hline \multirow{2}{*}{1} & (Constant) & 1.644 & .093 & & 17.671 & .000 & .378 & $18.52(.00)$ \\
\hline & Power to propose an idea/plan & .246 & .057 & .378 & 4.303 & .000 & & \\
\hline \multirow{3}{*}{2} & (Constant) & 1.837 & .114 & & 16.103 & .000 & .446 & $13.66(.00)$ \\
\hline & Power to propose an idea/plan & .246 & .055 & .378 & 4.430 & .000 & & \\
\hline & Monthly income & -.050 & .018 & -.237 & -2.773 & .007 & & \\
\hline \multirow{4}{*}{3} & (Constant) & 3.746 & .189 & & 19.843 & .000 & .790 & $60.46(.00)$ \\
\hline & Power to propose an idea/plan & .176 & .039 & .271 & 4.553 & .000 & & \\
\hline & Monthly income & -.024 & .013 & -.112 & -1.880 & .063 & & \\
\hline & Family hardiness & -.047 & .004 & -.673 & -11.118 & .000 & & \\
\hline \multirow{5}{*}{4} & (Constant) & 3.940 & .174 & & 22.609 & .000 & .835 & $62.46(.00)$ \\
\hline & Power to propose an idea/plan & .105 & .037 & .161 & 2.795 & .006 & & \\
\hline & Monthly income & -.024 & .011 & -.111 & -2.058 & .042 & & \\
\hline & Family hardiness & -.038 & .004 & -.546 & -9.124 & .000 & & \\
\hline & Family support & -.063 & .012 & -.325 & -5.123 & .000 & & \\
\hline
\end{tabular}

a. Dependent Variable: FAD: Family General Function, lower score of the FAD-GF presented healthy function

Group discussion on the modification of various health behaviors that would alter the lifestyles of the participants (e.g., reducing body weight or health risk by maintaining a normal lumbar/waist ratio or increasing frequency of relaxation exercises to manage stress) can have significant benefits. Specifically, this could provide assistance in the prevention of secondary health-related complications and alter their attitude towards coping with their current family functionality and health status. Furthermore, participants should be encouraged to manage their health based on the results of the health risk and nutritional needs assessment.

The findings from this study are important, as participants demonstrate the different associations of family health behavior with monthly income, education, and the power to propose an idea or plan. In addition, these results of the relationship between a family's overall functionality with respect to the power to propose an idea or plan and monthly income support the findings of others. Other studies have found that economic conditions significantly affect a family's adherence to diet [26]. The present study provides evidence that gender, education, income, time spent watching TV, and the power to propose an idea or plan constitute important characteristics influencing the family health promotion model. However, the major predictors influence on family general function are the power to propose an ides/ plan, family monthly income, family hardiness, and family support that construct accounted for $69.72 \%$ of the variance in family general function. The implication of the study present that family health promotion programs will provide to develop family hardiness and family support with stimulating families to develop the power to propose an idea/ plan in low income family.

The results of these relationships will assist nursing professionals with the development of an evaluation framework. This framework should include a minimum dataset and pay particular attention to the needs of rural populations. In addition, poverty has been found to be a common factor of emotional and behaviors in children of parents under financial stress $[27,28]$. This remains a problem, as highly trained nursing personnel have relocated from poor areas in developing countries in search of higher financial compensation or have neglected inefficient and inappropriate health systems. However, in the current study, we have only identified that health risks (waist/ lumbar ratio) are correlated with the family health behavior score. Ideally, researchers aim to prevent the development of chronic diseases through advocating family health promotion by identifying health risks (waist/ lumbar ratio). [29] Found that risk perception was correlated with family history of the disease and that an individual's perceived ability to prevent chronic disease was not related to familial risk factors.

Healthcare is deficient in DMD and SMA, families are important sources of interpersonal interaction that can influence commitment, challenge, or control of health-promotion behavior. Family members participate together in promoting healthy behavior, not only in the case of families of children with DMD and SMA, but also for the constructs of the family health promotion model as predictors of family health behavior. Nursing professionals play a fundamental role in supporting the health requirements of families of children with muscular dystrophy by encouragement and promotion of health by assessing health and lifestyle patterns. In addition, these healthcare professionals should intervene and help these families to facilitate positive behaviors. These habits are partly responsible for the unequal health status of different population groups.

Several studies of intervention with the intention of enhancing health promotion behavior on teenagers, provided evidence that self efficacy constitute a major predictor of physical activity [30]. Risk reduction, health maintenance, rehabilitation, and care giving are areas in which families often need information and assistance that will directly influence family support, domestic hardiness, general family health, and overall family functionality. In the future, additional consideration of collaboration with family support and hardiness should extend the capacity of a family to promote healthy behavior within the vulnerable population to be explored.

\section{Acknowledgements}

We would like to thank the Families of children with DMD and SMA For their contribution to the completion of this research. 


\section{Funding}

Worked was Funded by grant KMUH- N10004 \& KMU-M104024

\section{Ethical approval}

KMUH-IRB-20110397

\section{Contributions}

Study design: JYC; data collection and analysis: MCL, YHL, HSC, MHY, SHH, YYL; and manuscript preparation: JYC, HSC, MCL.

\section{References}

1. Robert Kliegman, Richard E. Behrman, Hal B. Jenson. Muscular dystrophies. Nelson Textbook of Pediatrics Philadelphia, Pa: Saunders Elsevier. 2007. p. 608.

2. ADAM Health Solutions. Duchenne muscular dystrophy. MedlinePlus Medical Encyclopedia: National Institutes of Health. 2014.

3. Chen JY, Jong YJ. A stress model for parents of children with Duchenne muscular dystrophy. Hu Li Za Zhi. 2006; 53(3): 44-51.

4. Chen JY, Clark MJ. Family resources and parental health in families of children with Duchenne muscular dystrophy. J Nurs Res. 2010; 18(4): 239-48. doi: 10.1097/JNR.0b013e3181fbe37b

5. Wang CH, Finkel RS, Bertini ES, Schroth M, Simonds A, Wong B, et al. Consensus statement for standard of care in spinal muscular atrophy. J Child Neurol. 2007; 22(8): 1027-49.

6. Biggar WD. Duchenne muscular dystrophy. Pediatrics in Review. 2006; 27(3): 83-88

7. Kostova FV, Williams VC, Heemskerk J, Iannaccone S, Didonato C, Swoboda K, et al. Spinal Muscular Atrophy: Classification, diagnosis, management, pathogenesis, and future Research Directions. J Child Neurol. 2007; 22(8): 926-45

8. Lunn MR, Wang CH. Spinal muscular atrophy. Lancet. 2008; 371(9630): 2120-33. doi: 10.1016/S0140-6736(08)60921-6.

9. Sackner MA. Diaphragmatic breathing exercises. Therapy in chronic obstructive pulmonary disease. JAMA. 1975; 231(3): 295-6.

10. Chen YH, Lin YH, Hung CS, Huang CC, Yeih DF, Chuang PY, et al. Clinical outcome and cost-effectiveness of a synchronous telehealth service for seniors and nonseniors with cardiovascular diseases: A quasi-experimental study. J Med Internet Res. 2013; 15(4): e87. doi: 10.2196/jmir.2091.

11. Chen JY. Mediators affecting family functioning in families of children with duchenne muscular dystrophy. Kaohsiung J Med Sci. 2008; 24(10): 514-22. doi: 10.1016/S1607-551X(09)70010-5.

12. Chen JY, Clark MJ. Family function in families of children with Duchenne muscular dystrophy. Fam Community Health. 2007; 30(4) 296-304.

13. Chen JY, Clark MJ, Chang YY, Liu YY, Chang CY. Factors affecting perceptions of family function in caregivers of children with attention deficit hyperactivity disorders. J Nurs Res. 2014; 22(3): 165-75. doi: 10.1097/jnr.0000000000000042.

14. Weiss JA, Robinson S, Fung S, Tint A, Chalmers P, Lunsky Y. Family hardiness, social support, and self-efficacy in mothers of individuals with Autism Spectrum Disorders. Research Research in Autism
Spectrum Disorders. 2013; 7(11): 1310-1317. doi:10.1016/j rasd.2013.07.016

15. George R. Parkerson. User's guide for Duke Health Measures. Durham, NC: Department of Community and Family Medicine, Duke University Medical Center. 2002

16. Epstein NB, Baldwin LM, Bishop DS. The McMaster Family Assessment Device. Journal of Marital and Family Therapy. 1983; 9(2): 171-180.

17. Kuo SC. Change in family functioning during perinatal period in high-risk pregnancy with preterm labor pattern [Chinese]. Nursing Research China. 1994; 2(2): 106-115.

18. McCubbin HI, Thompson AI, McCubbin MA. Family measures: Stress, coping, and resiliency --Inventories for research and practice. Honolulu, Hawaii: Kamehameha Schools. 2001.

19. Smilkstein G. The Family APGAR: A proposal for a family function test and its use by physicians. J Fam Pract. 1978; 6(6): 1231-9.

20. Smilkstein G, Ashworth C, Montano D. Validity and reliability of the Family APGAR as a test of family function. J Fam Pract. 1982; 15(2): 303-11.

21. Chen MY, Wang EK, Chang CJ. Cross-validation and discriminant validity of Adolescent Health Promotion Scale among overweight and non-overweight adolescents in Taiwan. Public Health Nurs. 2006; 23(6): 555-60.

22. Brolin C, Shiraishi T. Antisense mediated exon skipping therapy for duchenne muscular dystrophy (DMD). Artif DNA PNA XNA. 2011; 2(1): 6-15.

23. Parkerson GR Jr, Broadhead WE, Tse CK. The Duke health profile: A 17-item measure of health and dysfunction. Med Care. 1990; 28(11): 1056-72.

24. Faul F, Erdfelder E, Buchner A, Lang AG. Statistical power analyses using G*Power 3.1: Tests for correlation and regression analyses. Behav Res Methods. 2009; 41(4): 1149-60. doi: 10.3758/BRM.41.4.1149.

25. Faul F, Erdfelder E, Lang AG, Buchner A. G*Power 3: A flexible statistical power analysis program for the social, behavioral, and biomedical sciences. Behav Res Methods. 2007; 39(2): 175-91.

26. Aggarwal B, Liao M, Allegrante JP, Mosca L. Low social support level is associated with non-adherence to diet at 1 year in the Family Intervention Trial for Heart Health (FIT Heart). J Nutr Educ Behav. 2010; 42(6): 380-8. doi: 10.1016/j.jneb.2009.08.006.

27. Grant KE, McCormick A, Poindexter L, Simpkins T, Janda CM, Thomas $\mathrm{KJ}$, et al. Exposure to violence and parenting as mediators between poverty and psychological symptoms in urban African American adolescents. J Adolesc. 2005; 28(4): 507-21.

28. Mejia A, Calam R, Sanders MR. A Review of parenting programs in developing countries: Opportunities and challenges for preventing emotional and behavioral difficulties in children. Clin Child Fam Psychol Rev. 2012; 15(2): 163-75. doi: 10.1007/s10567-012-0116-9.

29. Acheson LS, Wang C, Zyzanski SJ, Lynn A, Ruffin MT 4th, Gramling $\mathrm{R}$, et al. Family history and perceptions about risk and prevention for chronic diseases in primary care: A report from the family healthware impact trial. Genet Med. 2010; 12(4): 212-8. doi: 10.1097/ GIM.0b013e3181d56ae6.

30. Srof BJ, Velsor-Friedrich B. Health promotion in adolescents: A review of pender's health promotion model. Nurs Sci Q. 2006; 19(4): 366-73. 